\title{
REFLECTIONS
}

\section{It's Not You, It's Me: Learning to Navigate the Patient-Physician Relationship}

\author{
Melissa B. Hill \\ Icahn School of Medicine at Mount Sinai, \\ New York, New York
}

\begin{abstract}
In this essay, a medical student details how she struggled to let go of a patient with whom she connected throughout the patient's pregnancy during her second year of medical school. Although she learned in her preclinical "doctoring" courses how to build quick connections with patients, such training did not delve into how to manage meaningful, emotionally complex connections that may form with patients during longitudinal rotations or, as in this case, extracurricular activities. While primary care physicians may have decades of practice managing evolving longitudinal relationships, medical students who form strong connections with patients are just learning what it means to navigate those relationships, some of which come to an end. Reflecting on the end of this particular relationship helped the author appreciate the power of the longitudinal physician-patient relationship and taught her that taking care of patients also requires taking care of one's self.
\end{abstract}

Ann Fam Med 2021;19:271-273. https://doi.org/10.1370/afm.2644.

T The first time I met her, she greeted me with a hug and kissed me on both cheeks. She was 29 years old and 16 weeks pregnant with her third child. As a second-year student, I had been paired with Lina* through a program at my medical school that aims to support expectant mothers with limited resources and without other support systems during their pregnancies. I was drawn to this program when I started medical school because my clinical interest is in primary care, and I feel strongly about advocating for expanded access to reproductive health care. Attending medical school on the border between two of the richest and poorest zip codes in New York City, I saw firsthand how socioeconomic status impacted both health and comfort in pregnancy. Despite her somewhat limited English proficiency-we conversed mostly in Spanish—and our different socioeconomic upbringings, Lina and I are not so different at heart; we are close in age, like the same kind of music, dedicate our waking hours to caring for those in need, and make friends with anyone we meet. She is a caregiver in every sense of the word: she is a mother, she works as a home health aide, and she is exceptionally warm and attentive, always concerned with the health and happiness of everyone around her.

Given her prior medical conditions, Lina's pregnancy was designated as high-risk, meaning she had an appointment at the hospital nearly every week of her pregnancy. I attended most of those appointments. I would show up a few minutes before the scheduled appointment time, talk with her one-on-one in the waiting room during the inevitable delay in the clinic schedule, and I would sit with her through her appointment. Even on a day when everything moved smoothly in the clinic, I would spend around an hour with her, talking briefly about what I was learning, and then listening attentively as she described struggles she had with family, work, and housing in the last week. My heart ached for her, and yet the boundaries laid out by the faculty supervising these partnerships were clear ${ }_{i}$ it was not my 
place to intervene in any social matters. My role was to provide company, companionship, and consistency for young mothers without the same extensive support network during pregnancy as expectant mothers in a more secure socioeconomic position.

Our relationship deepened throughout her pregnancy. We shared stories of our mothers-hers waiting on a visa in South America, mine only 25 blocks awayand I felt her yearning. At times, I felt guilty for having taken for granted the proximity of my own familial support system. I sensed her frustration in having to drop out of nursing school classes because of limited time between single parenting and her day job. She had her first child at age 19 and her second at 26. I shared her concern as she described how her 10-year-old daughter was acting out in school and how her 3-year-old son wanted desperately to be the man of the house. As her due date approached, she occasionally asked for my opinion on matters of her health care, like what kind of pain medication was best during delivery. Wishing I could do more, but knowing the limitations of my medical experience as well as the program's proscriptions, I'd offer to look over the options together and remind her this was a decision best made with her doctor.

A few nights before her due date, Lina texted me that she was going into labor. I live across from the hospital, and I took a study break to meet her at checkin. The attending physician asked me to put on scrubs so I could help during the delivery. I held one of her legs, a nurse held the other. We encouraged her in English and Spanish until she delivered a healthy baby boy.

According to the guidelines of the program that matched us, our partnership was supposed to end with her 6-week postpartum appointment. At that appointment, when the baby started crying as Lina was talking to the physician, she instinctively handed him to me for comfort. Holding her baby, I thought to myself, "Was Lina my patient? My friend? My client?" I didn't even know how to identify our relationship. "I'm so blessed to have you here," she'd tell me at every visit. I cared about her and her baby, and I had spent an enormous amount of time and invested a great deal emotionally following and supporting her pregnancy. It made me smile to receive texts and calls from her after the postpartum appointment, many with pictures of the baby. I knew that the guidelines of the program-which were in place to prevent misunderstandings in patient care delivery-instructed me to let go so I could partner with a new expectant mom and Lina could transition to new care providers. But the guidelines don't address how to end our partnership, and it made me miserable to feel like I was abandoning a good friend.

My experience is not unique. In the brief few months that medical students may join a patient's care team, they use skills emphasized in preclinical "doctoring" courses to build trusting relationships with patients. But when the rotation or longitudinal activity comes to a close, they have to end those relationships, while the supervising physician does not. Students don't sufficiently learn how to navigate these connections, and certainly not how to end them, yet these experiences, which come early in clinical education, can greatly shape their practice as future physicians.

In thinking about why my relationship with Lina may have been so formative, and how it may differ for me as a medical student from the relationships I intend to form with patients as a physician in the future, two main considerations - the nature and timeline of our relationship-come to mind. While the patient-provider relationship is, at its core, a fiduciary relationship, this somewhat contractual definition fails to embrace the profound effect that a longitudinal patient-provider relationship may have on improving a patient's health and well-being. ${ }^{1}$ Patients may reveal their most intimate and confidential concerns only with a trusted health care provider. And where depersonalization of medical practice may be a contributing factor to emotional exhaustion amongst providers, forming meaningful, long-term relationships with patients may be a protective factor against physician burnout. ${ }^{2}$ My relationship with Lina fulfilled the purpose of supporting her throughout vulnerable months of her pregnancy, and hopefully contributed to promoting her health during pregnancy. Our connection also supported my emotional health, serving as a weekly reminder of why I'm drawn to primary care and why I love medicine despite the stressors of medical school. However, our relationship was still distinct from how I imagine future patient relationships. Though longitudinal on a smaller scale, it was still designed to be relatively short-term. It was not fiduciary in nature, as some patient-provider relationships may be. And while I knew personal details about her life, she also knew about my family, my schoolwork, and my career goals. Perhaps these distinctions are why it carried more weight than my other patient encounters, and why the end of our relationship created such internal conflict for me.

Primary care clinicians ultimately have years or decades of experience navigating these relationships in ways that can be sufficiently flexible, healthy, and respectful for both parties. As a medical student, I am just learning. And although standardized patient encounters may teach students how to quickly garner patient trust upon introduction, this does not address the nuances of managing the evolution of longitudinal patient-physician relationships which may, over years, include times of conflict, grief, and adversity. Trainees must learn ways to bestow respect, empathy, and 
compassion upon patients in trying moments while upholding the emotional well-being of both parties. For this, I turn to my clinical mentors, asking that they share stories and lessons guided by their own personal experiences so that I might be better equipped for the future, understanding that each clinician must find their authentic voice in these relationships.

Every few weeks after Lina's postpartum visit, I'd receive a text from her asking how I was doing, just as I often ask of close friends. She inquired about my classes, and I inquired about how her kids were adjusting to the baby. She would thank me again for the support, and say that she missed me. Truthfully, I missed her, too. Our small talk over text continued for awhile, eventually becoming less and less frequent, and coming to a natural end a few months later. Had the guidelines been more flexible, maybe we could have continued to connect every so often to share career updates or stories about our families, and maybe this would have facilitated a goodbye that was less painful.

My experience with Lina opened my eyes to the complex and rewarding nature of longitudinal relationships, even if they may eventually come to an end. I look forward to forming bonds with my patients, and I am learning to be cognizant of my own emotional well-being even as I care for someone else's. Perhaps more comprehensive training by my supervising faculty could have better prepared me for the end of my partnership with Lina, but I believe this is a lesson I will learn throughout my career. I will continue to develop the skills necessary to have successful longitudinal patient relationships as those relationships go through the natural cycles of life-conflict, joy, setbacks, and successes. I imagine my mentors may still be learning, too, how to mold their role as a health care provider to best accommodate the needs of their patients while attending to their own needs as well.

I still think about Lina often. I wonder how she's doing and what milestones her baby might have reached by now. Did her mother get her visa? Is the baby walking? How are her older children? I reflect on our partnership and its dissolution, questioning whether it was as formative for her as it was for me. I know that if I ran into Lina on the street years from now, she'd still wrap me up in a hug and kiss me on both cheeks like she did the first time we met. For now, I hope she is happy.

To read or post commentaries in response to this article, go to https://www.AnnFamMed.org/content/19/3/271/tab-e-letters.

Key words: personal narratives; personal narratives as topic; communication; empathy; narration; narrative medicine / trends; physicianpatient relations; therapeutic alliance; medical school

*Patient's name has been changed.

Disclaimer: I declare that this manuscript is original, has not been previously published and is not currently under consideration by any other journal. I have no conflicts of interest associated with this publication.

\section{References}

1. Chipidza FE, Wallwork RS, Stern TA. Impact of the doctor-patient relationship. Prim Care Companion CNS Disord. 2015;17(5).

2. West CP, Dyrbye LN, Shanafelt TD. Physician burnout: contributors, consequences and solutions. J Intern Med. 2018;283(6):516-529. 